\title{
Identification and characteristics of postnatal development-related long non-coding RNAs under microbiota dependent condition
}

Miaomiao Zheng ( $\square$ miaomiao_0000@126.com )

Harbin University

Binbin Zhang

Harbin University

Yidan Zhang

Harbin University

Tingting Sun

Harbin University

Baozhong Hu

Harbin University

Primary research

Keywords: long-non coding RNAs, microbiota, intestinal epithelial cells, postnatal development, gene

Posted Date: May 5th, 2020

DOI: https://doi.org/10.21203/rs.3.rs-26204/v1

License: (c) (1) This work is licensed under a Creative Commons Attribution 4.0 International License. Read Full License 


\section{Abstract}

\section{Background}

The interplay of long-non coding RNAs (IncRNAs) and the intestinal microbiota may serve as an essential role in intestinal development and homeostasis. Microbiota could regulate a large numbers of IncRNAs expression in intestinal epithelial cells. However, the associations between IncRNAs and microbiota during early postnatal development stages are still need to understand.

\section{Methods}

In present study, the microbial effects on IncRNA of intestinal epithelial cells (IECs) during postnatal development stage were investigated.

\section{Results}

We identified gut microbiota-specific IncRNAs in diverse postnatal development stages including week 1 , week 4 and week 12/16 of mice. A large proportion of gut microbiota-specific IncRNAs only were differential expressed in a single postnatal development stage. Up- and down-regulated gut microbiotaspecific IncRNAs both showed consistent expression pattern. We also constructed gut microbiota-specific IncRNAs and coding genes interacted co-expressed networks. Functional analysis indicated that gut microbiota-specific IncRNAs were associated with $A B C$ transporters.

\section{Conclusions}

In summary, the present study characterizes the landscape of IncRNAs associated with gut microbiota in different postnatal development stages. It provide assistance for exploring the relationships among IncRNAs, gut microbiota and postnatal development stages.

\section{Background}

Postnatal development is a key period in which the interaction between an individual and the environment has a lifelong impact on health and well-being, and it is an extension of the concept of "fetal origin of health and disease" [1]. Combined action of metabolic, complex functional and structural mechanisms contribute to infant growth during the early postnatal period [2]. The organism did not fully mature at birth, so the process of maturation continued for some time after birth [3,4]. More and more studies reveal that early postnatal development is associated with risk of disease in adulthood based on human and animal studies [5]. Many factors such as immune, nutrition, hormones and so on all can influence postnatal development $[1,6,7]$. Development of mammalian gastrointestinal is an important and essential part of postnatal development. Intestinal epithelial cells (IECs) play a central role in gastrointestinal [8]. Thus, ongoing researches should be need to explore the potential mechanism of postnatal development. 
Over time, bacteria and other microorganisms have evolved together with their multicellular hosts to form a unique micro ecosystem, namely microbiota [9]. The human body is not a closed and sterile system. Microorganisms can be implanted into skin [10], gastrointestinal tract [11], respiratory tract [12], urogenital tract and other open surfaces, and develop into a local microbial community with unique characteristics. Gut microbiota is also an essential influenced factor in postnatal development. Many kinds of metabolic processes including energy homeostasis, glucose metabolism and lipid metabolism are regulated by gut microbiota $[13,14]$. Imbalance of gut microbiota is related to metabolic perturbations during postnatal development process. In recent years, a trickle of studies have examined that lack of contact with environmental microbiota during early development stage maybe contribute to immune deficiency and advanced autoimmune diseases [15-17]. However, the functions of gut microbiota in postnatal development are still need to study.

Long non-coding RNA (IncRNA) is considered as an important type of non-coding RNA follow a series of researches $[18,19]$. The biological function and molecular mechanisms of IncRNA in many kinds of human diseases in particular are constantly revealed $[20,21]$. Besides diseases, the role of IncRNA in development also has been reported [22]. LncRNAs have been reported that not expressed at each certain stages in development. Expression of a IncRNA in a specific development stage indicate that it may have an important biological function at that time [23, 24]. For example, Phillip Grote et al. report that IncRNA locus Handsdown ( $\mathrm{Hdn}$ ) is active in early heart cells and essential for murine development [25]. The IncRNA Pnky is a trans-acting regulator of cortical development in vivo [26]. Wang et al. demonstrate that conserved IncRNAs at the nonimprinting regions in brain are essential for zebrafish development [27]. Although there are some evidences suggest that the important biological function and molecular mechanisms of IncRNA in postnatal development, their global ans systematic functions in development including gastrointestinal development remains largely unexplored. The associations among gut microbiota, development and IncRNA are also need to be in depth description and exploration.

In present study, IncRNAs could become as specific biomarkers for dividing mice samples of diverse postnatal development stages. Gut microbiota-specific IncRNAs were identified and analyzed in diverse postnatal development stages. Most of these gut microbiota-specific IncRNAs only differential expressed in a single postnatal development stage. Up- and down-regulated gut microbiota-specific IncRNAs showed consistent expression pattern. Gut microbiota-specific IncRNAs and coding genes interacted coexpressed networks were constructed. These gut microbiota-specific IncRNAs were associated with ABC transporters. Collectively, the results of the present study indicated that gut microbiota-specific IncRNAs could serve as essential roles in postnatal development stages.

\section{Results}

\section{Samples similarity and difference of samples based on IncRNA transcriptome under diverse postnatal development stages and condition}


In order to explore similarity and difference of samples based on IncRNA transcriptome under diverse postnatal development stages and condition. Hierarchical clustering method based on the PCCs was performed. We found all the samples of week 1 were clustered together (Fig. 1A). Samples of week 4 and week 12/16 cluster together obviously and couldn't distinguish. The result indicated that samples of week 1 showed stronger similarity on IncRNA level. CONV and GF samples also could be distinguished at some extent. The results of PCA for IncRNA expression showed first three PCs had most proportion of variance (Fig. 1B). Especially, the first PC accounts for $85 \%$. Thus, the first three PCs were analyzed and showed, separately. Samples of week1 were separated from other two stages including week 4 and week 12/16 according to both the developmental stage and microbial status based on PC1 and PC2 (Fig. 1C). It indicated that IncRNA expression changed dramatically during maturation of IECs, especially in the early postnatal period. In addition, PC2 also could distinguish CONV and GF within single developmental week 1 stage. PC3 could separated week 4 and week 12/16 (Fig. 1D, E). Thus, these first three PCs showed outperformance on distinguishing developmental stage and microbial status. All the results indicated that IncRNA expression could serve as effective biomarkers for developmental stage and microbial status.

\section{Some IncRNAs were differential expressed between CONV and GF mice in diverse postnatal development stages}

In order to further explore roles of IncRNAs for microbiota in diverse postnatal development stages, differential expressed IncRNAs between CONV and GF mice were identified. In each postnatal development stage, a certain number of differential expressed IncRNAs were identified. For example, there was 20 differential expressed IncRNAs in week 1 (Fig. 2A). In week 4 and week 12/16 CONV and GF mice, 21 and 42 differential expressed IncRNAs were identified (Fig. 2B, 2C). We also describe the interactions of differential expressed IncRNAs among three diverse kinds of postnatal development stages. We found there is little intersection between these differential expressed IncRNAs in diverse postnatal development stages (Fig. 2D). It also indicated that microbiota-specific IncRNAs showed diverse expression pattern during postnatal development. Different microbiota-related IncRNAs serve as their roles at specific postnatal development stage.

\section{Differential expressed IncRNAs between CONV and GF mice showed specific features in respective postnatal development stage}

All above results revealed that microbiota-related IncRNAs showed significant differences in diverse postnatal development stage. Thus, we further depicted the specific features of microbiota-related IncRNAs in respective postnatal development stage. We divided all the microbiota-related IncRNAs to upand down-regulated microbiota-related IncRNAs. In mice with week 1, there were 6 and 14 up- and down- 
regulated microbiota-related IncRNAs. The expression pattern of up- and down-regulated microbiotarelated IncRNAs were almost consistent (Fig. 3A, B). For example, fold-change values of almost all downregulated microbiota-related IncRNAs showed declining trend. Fold-change values of almost all downregulated microbiota-related IncRNAs showed rising trend. Similar pattern were also present in week 4 and week 12/16 (Figure S1). We also discovered that some up- and down-regulated IncRNAs showed similar expression patterns and clustered together (Fig. 3C, D). Specially, up-regulated IncRNAs Gm13067, Gm37459, F630040K05Rik, 4930519L02Rik, Gm16137 and Gm16540 form an independent cluster, obviously. Similarly, up- and down-regulated IncRNAs in other postnatal development stages also clustered diverse groups (Figure S2). Collectively, differential expressed IncRNAs between CONV and GF mice showed specific expression in diverse postnatal development stage. However, these IncRNAs also showed similar expression pattern in respective postnatal development stage.

\section{Gut microbiota-specific IncRNA and protein coding gene interaction networks were constructed at different postnatal development stages}

In order to describe biological mechanisms of gut microbiota-specific IncRNAs, IncRNA and protein coding gene interaction networks at different postnatal development stages were constructed. All the interactions were filtered by co-expression of IncRNAs and genes. Gut microbiota-specific IncRNA and gene interaction network in week 1 contained 11 IncRNAs and 209 genes (Fig. 4A). Only a little number of IncRNAs and genes had high degree in the network (Fig. 4B, C). It maybe could serve as a degree pattern of scale-free network. In addition, Gut microbiota-specific IncRNA and gene interaction network in week 4 contained 15 IncRNAs and 562 genes (Fig. 4D). Gut microbiota-specific IncRNA and gene interaction network in week 12/16 contained 31 IncRNAs and 461 genes (Fig. 4E). The degree of genes and IncRNAs in week 4 and week 12/16 also showed similar patterns which are only a small part of genes and IncRNAs had higher degree (Figure S3). The results revealed that gut microbiota-specific IncRNA could serve their roles by interacting with some genes in diverse postnatal development stages. Moreover, these gut microbiota-specific IncRNA and protein coding gene interaction networks showed specific features of meaningful biological network.

\section{Gut Microbiota-specific Lncrnas Were Associated With Eukaryotic-type Abc Transporters}

In order to further explore the biological functions of gut microbiota-specific IncRNAs in diverse postnatal development stages, functional analyses were performed for their interacted genes. In week 1, gut microbiota-specific IncRNAs were associated with key pathways including Rap1 signaling pathway, cAMP signaling pathway, Axon guidance and ATP Binding Cassette (ABC) transporters (Fig. 5A). In week 4, gut microbiota-specific IncRNAs were associated with key pathways including RNA transport, RNA 
degradation, regulation of actin cytoskeleton, $A B C$ transporters and so on (Fig. 5B). In week 12/16, gut microbiota-specific IncRNAs were associated with key pathways including tight junction, Rap1 signaling pathway, focal adhesion, $A B C$ transporters and so on (Fig. 5C). The gut microbiota-specific IncRNAs showed different functions in diverse postnatal development stages. Notably, ABC transporters pathway was a key and common pathway which were associated with gut microbiota-specific IncRNAs in all postnatal development stages. Accumulating evidence reported that $A B C$ transporters could regulate the absorption, distribution, metabolism, secretion and toxicity of xenobiotics [28]. Thus, we inferred that these gut microbiota-specific IncRNAs may play their role in postnatal development by participating in $A B C$ transporters pathway. Previous study indicated that there were potential associations between $A B C$ transporters of the intestinal epithelial cell barrier and gut microbes in health and disease [29].

Transporters belonging to the ABC superfamily couple the energy released from ATP hydrolysis to the translocation of a wide variety of substances into or out of cells and organelles [30]. ABC transporter is one of the largest known protein superfamily and there are $48 \mathrm{ABC}$ transporters in humans. Yin et al. reported that there were close relationships among $A B C$ transporters pathway, gut microbiota and obesity in chinese children and adolescents [31]. $A B C A$ and $A B C C$ were two major subfamilies in $A B C$ transporters (Fig. 5D). Some key genes in these two subfamilies could interact with gut microbiotaspecific IncRNAs (Fig. 5E). And, most of them showed high degree. These results indicated that gut microbiota-specific IncRNAs could influence $A B C$ transporters pathway in postnatal development stages.

\section{Discussion}

Here, gut microbiota-specific IncRNAs at different postnatal development stages were identified and characterized. Gut microbiota-specific IncRNAs almost had no intersections among diverse postnatal development stages. These gut microbiota-specific IncRNAs showed specific expression pattern in respective postnatal development stage. Moreover, some gut microbiota-specific IncRNAs could cluster together in a postnatal development stage. Gut microbiota-specific IncRNAs were associated with eukaryotic-type ABC transporters based on genes and IncRNAs co-expressed interacted networks.

Accumulating evidence reported that gut microbiota were associated with multiple kinds of diseases including colon cancer [32], gestational diabetes [33], type 1 diabetes [34], cardiovascular disease [35] and so on. In addition, biological processes containing diet, weight [36], bone homeostasis [37] and postnatal development were also influenced by gut microbiota. Most of previous studies about gut microbiota focused on coding genes. In our work, gut microbiota-specific IncRNAs were identified in diverse postnatal development stage. Most of these IncRNAs only showed high expression in a specific postnatal development stage. Differential expressed IncRNAs almost had no intersections among diverse postnatal development stages. It revealed that most IncRNAs were time limited in postnatal development process. In addition, these IncRNAs also showed tissue specificity. The gut microbiota-specific IncRNAs and coding genes interacted networks revealed that IncRNAs served as their roles by regulating coding genes. These results enriched our understanding about biological mechanisms of gut microbiota in postnatal development. 
Moreover, functional analysis indicated that gut microbiota-specific IncRNAs in diverse postnatal development stages were associated with eukaryotic-type $A B C$ transporters. ABC transporter, a ubiquitous membrane protein superfamily, is involved in ATP driven transmembrane lipid bilayer substrate transport of cellular membranes [38]. Over the years, a large number of studies reported that $A B C$ transporters participated in several fundamental cellular functions such as regulating cellular levels of lipids, hormones, ions by transporting peptides and cholesterol that serve as essential roles in a relevant number of genetic diseases $[39,40]$. Bacteria use $A B C$ transporters either as importers to bring nutrients and other molecules into cells or as exporters to pump toxins or other undesirable substances out of the cell. In our study, we also found gut microbiota-specific IncRNAs were also related to ABC transporters.

\section{Conclusions}

In summary, the present study identified and characterized gut microbiota-specific IncRNAs in diverse postnatal development stages. These gut microbiota-specific IncRNAs showed different expression pattern in diverse postnatal development stages. They served as roles by participating in eukaryotic-type $A B C$ transporters in postnatal development stages. Our study could provide assistance for clarifying biological mechanisms and functions of IncRNAs in gut microbiota and postnatal development.

\section{Materials And Methods}

\section{Collection of gut microbiota transcriptome during postnatal development stages of mice}

The transcription data about small intestine of mice testing by RNA-seq technology was download from GEO (Gene Expression Omnibus, https://www.ncbi.nlm.nih.gov/geo/) database (under accession number: GSE94402, https://www.ncbi.nlm.nih.gov/geo/query/acc.cgi?acc=GSE94402). The small intestine of mice were treated under two different conditions, conventional-raised mice (presence of microbiota, refers as CONV in our analysis) and germ-free mice (absence of microbiota, refers as GF in our analysis). All the mice were sacrificed at three different stages: 1, 4 and between 12 to 16 weeks of age. IECs were collected from the small intestine of 1-, 4- and 12 to 16-week-old mice, raised either in the presence or absence of a microbiota. The detailed information could be found in previous study [41].

\section{Obtain of IncRNA profile in mice with and without gut microbiota during diverse postnatal development stages}

We got IncRNA annotation file of mice from GENCODE database (vM23, https://www.gencodegenes.org/) [42], and subtracted IncRNA read counts information from the transcription data provided by previous dataset GSE94402. We calculated FPKM expression level according to the covering reads and IncRNA length. During this process, the IncRNAs that are expressed in at least half samples were retained. All the expression values of IncRNAs were transformed by log2 to satisfy the normal distribution. 


\section{Explore similarity and difference of samples based on IncRNA transcriptome under diverse postnatal development stages and condition}

We evaluated sample similarity by Pearson correlation method using IncRNAs expression profiles. Then, we clustered samples to divide diverse groups using hierarchical clustering method based on the Pearson Correlation Coefficients (PCCs). This process was performed by pheatmap package as implemented in R program. Principle component analysis (PCA) was also performed for mice using IncRNAs expression level. We used the first 3 principle components (PCs) to visualize sample distribution.

\section{Identification of differential expressed IncRNAs between CONV and GF mice}

For each age state of mice, $T$ test and fold change methods were performed to identify differential expressed IncRNAs by comparing the IncRNA expression profiles of CONV and GF mice. LncRNAs with $p$ $<0.01$ and $|\log 2(\mathrm{CONV} / \mathrm{GF})|>1$ were identified as differential expressed IncRNAs. Intersections of differentially expressed IncRNAs sets in each stage were got.

\section{Altering features of differential expressed IncRNAs between CONV and GF mice in diverse postnatal development stages}

According to the IncRNA expression changes between CONV and GF condition, we divided IncRNAs into up- $(\log 2(\mathrm{CONV} / \mathrm{GF})>1)$ and down-regulated $(\log 2(\mathrm{CONV} / \mathrm{GF})<1)$ sets. For the up/down-regulated IncRNAs in each postnatal development stage, we calculated spearman correlation coefficients using fold levels (log2(CONV/ GF)) of IncRNA expression, and clustered IncRNAs using hierarchical clustering method in pheatmap package as implemented in $\mathrm{R}$ program.

\section{Construction of gut microbiota-specific IncRNA and protein coding gene interaction networks at different postnatal development stages}

The experimentally validated and computationally predicted RNA and protein interacted data was collected from RNAInter repository (RNA Interactome Database, http://www.rna-society.org/raid/) [43]]. We extracted interactied entries which RNA type annotated as "IncRNA" and species type annotated as "Mus musculus". Then, we mapped our identified differentially expressed IncRNAs into the obtained IncRNA-protein relationships. For the relationships at each postnatal development stage, we tested 
IncRNA and the corresponding mRNA correlations by pearson correlation test using expression profiles. The significant correlated IncRNA-protein pairs $(p<0.01)$ were retained and visualized by cytoscape 3.3.0 software (https://cytoscape.org/).

\section{Functional enrichment analysis of differential expressed IncRNAs in diverse postnatal development stages}

For each postnatal development stage, functional enrichment analysis was performed using the IncRNA correlated proteins by enrichr web server (http://amp.pharm.mssm.edu/Enrichr/) [44], and get significant enriched pathways in mouse $(p<0.01)$. Enriched pathways were visualized by bubble plots. LncRNA and protein relationships in all postnatal development stages of the interested pathways were also visualized using cytoscape software.

\section{Declarations}

\section{Competing interests}

The authors declare that they have no competing interests.

\section{Funding}

This work was supported by the Funding for the Postdoctoral Foundation of Heilongjiang Province (grant numbers: LBH-Z18028), National innovation and entrepreneurship training program for College Students (grant number: 201910234015 and 201910234018 ).

\section{Authors' contributions}

ZMM conceived and designed the experiments, ZBB, ZYB, and HBZ analyzed the data, ZMM and STT validated the work, and ZMM wrote the manuscript.

\section{Acknowledgments}

Not applicable.

\section{Disclosure of interest}

The authors declare that they have no competing interest. 


\section{Ethics approval and consent to participate}

Not applicable.

\section{Patient consent for publication}

Not applicable.

\section{Consent for publication}

Not applicable

\section{References}

1. Bell MR. Comparing Postnatal Development of Gonadal Hormones and Associated Social Behaviors in Rats, Mice, and Humans. Endocrinology 2018, 159, (7), 2596-2613.

2. Ost'adalova I, Babicky A. Periodization of the early postnatal development in the rat with particular attention to the weaning period. Physiological research. 2012;61(Suppl 1):1-7.

3. Patel MS, Srinivasan M. Metabolic programming due to alterations in nutrition in the immediate postnatal period. J Nutr. 2010;140(3):658-61.

4. Patel MS, Srinivasan M. Metabolic programming in the immediate postnatal life. Ann Nutr Metab. 2011;58(Suppl 2):18-28.

5. Eleftheriades M, Creatsas G, Nicolaides K. Fetal growth restriction and postnatal development. Ann N Y Acad Sci. 2006;1092:319-30.

6. Helbling PM, Pineiro-Yanez E, Gerosa R, Boettcher S, Al-Shahrour F, Manz MG, Nombela-Arrieta C. Global Transcriptomic Profiling of the Bone Marrow Stromal Microenvironment during Postnatal Development, Aging, and Inflammation. Cell reports. 2019;29(10):3313-30 e4.

7. Rossetti MF, Schumacher R, Gastiazoro MP, Lazzarino GP, Andreoli MF, Stoker C, Varayoud J, Ramos JG. Epigenetic Dysregulation of Dopaminergic System by Maternal Cafeteria Diet During Early Postnatal Development. Neuroscience. 2020;424:12-23.

8. Peterson LW, Artis D. Intestinal epithelial cells: regulators of barrier function and immune homeostasis. Nat Rev Immunol. 2014;14(3):141-53.

9. Schopf JW, Packer BM. Early Archean (3.3-billion to 3.5-billion-year-old) microfossils from Warrawoona Group, Australia. Science 1987, 237, 70 - 3.

10. Belkaid Y, Segre JA. Dialogue between skin microbiota and immunity. Science 2014, 346, (6212), 954-9.

11. Rajilic-Stojanovic M, Smidt H, de Vos WM. Diversity of the human gastrointestinal tract microbiota revisited. Environ Microbiol. 2007;9(9):2125-36. 
12. Man WH, de Steenhuijsen Piters WA, Bogaert D. The microbiota of the respiratory tract: gatekeeper to respiratory health. Nature reviews. Microbiology 2017, 15, (5), 259-270.

13. Schoeler M, Caesar R. Dietary lipids, gut microbiota and lipid metabolism. Reviews in endocrine metabolic disorders. 2019;20(4):461-72.

14. Sonnenburg JL, Backhed F. Diet-microbiota interactions as moderators of human metabolism. Nature 2016, 535, (7610), 56-64.

15. Gensollen T, lyer SS, Kasper DL, Blumberg RS. How colonization by microbiota in early life shapes the immune system. Science 2016, 352, (6285), $539-44$.

16. Olszak T, An D, Zeissig S, Vera MP, Richter J, Franke A, Glickman JN, Siebert R, Baron RM, Kasper DL, Blumberg RS. Microbial exposure during early life has persistent effects on natural killer T cell function. Science 2012, 336, (6080), 489 - 93.

17. Sudo N, Chida Y, Aiba Y, Sonoda J, Oyama N, Yu XN, Kubo C, Koga Y. Postnatal microbial colonization programs the hypothalamic-pituitary-adrenal system for stress response in mice. The Journal of physiology 2004, 558, (Pt 1), 263-75.

18. Quinn JJ, Chang HY. Unique features of long non-coding RNA biogenesis and function. Nat Rev Genet. 2016;17(1):47-62.

19. Uszczynska-Ratajczak B, Lagarde J, Frankish A, Guigo R, Johnson R. Towards a complete map of the human long non-coding RNA transcriptome. Nat Rev Genet. 2018;19(9):535-48.

20. Ling H, Vincent K, Pichler M, Fodde R, Berindan-Neagoe I, Slack FJ, Calin GA. Junk DNA and the long non-coding RNA twist in cancer genetics. Oncogene 2015, 34, (39), 5003-11.

21. Luo X, Qiu Y, Jiang Y, Chen F, Jiang L, Zhou Y, Dan H, Zeng X, Lei YL, Chen Q. Long non-coding RNA implicated in the invasion and metastasis of head and neck cancer: possible function and mechanisms. Mol Cancer. 2018;17(1):14.

22. Tsagakis I, Douka K, Birds I, Aspden JL, Long non-coding RNAs in development and disease: Conservation to mechanisms. The Journal of pathology 2020.

23. Kuang L, Lei M, Li C, Guo Z, Ren Y, Zhang X, Zheng J, Zhang C, Yang C, Mei X, Tang L, Ji Y, Deng X, Yang $\mathrm{R}$, Xie $\mathrm{X}$. Whole transcriptome sequencing reveals that non-coding RNAs are related to embryo morphogenesis and development in rabbits. Genomics 2020, 112, (3), 2203-2212.

24. Zhu J, Yu W, Wang Y, Xia K, Huang Y, Xu A, Chen Q, Liu B, Tao H, Li F, Liang C. IncRNAs: function and mechanism in cartilage development, degeneration, and regeneration. Stem Cell Res Ther. 2019;10(1):344.

25. Ritter N, Ali T, Kopitchinski N, Schuster P, Beisaw A, Hendrix DA, Schulz MH, Muller-McNicoll M, Dimmeler S, Grote P. The IncRNA Locus Handsdown Regulates Cardiac Gene Programs and Is Essential for Early Mouse Development. Developmental cell. 2019;50(5):644-57 e8.

26. Andersen RE, Hong SJ, Lim JJ, Cui M, Harpur BA, Hwang E, Delgado RN, Ramos AD, Liu SJ, Blencowe BJ, Lim DA. The Long Noncoding RNA Pnky Is a Trans-acting Regulator of Cortical Development In Vivo. Developmental cell. 2019;49(4):632-42. e7. 
27. Wang F, Ren D, Liang X, Ke S, Zhang B, Hu B, Song X, Wang X. A long noncoding RNA cluster-based genomic locus maintains proper development and visual function. Nucleic acids research. 2019;47(12):6315-29.

28. Leslie EM, Deeley RG, Cole SP. Multidrug resistance proteins: role of P-glycoprotein, MRP1, MRP2, and BCRP (ABCG2) in tissue defense. Toxicol Appl Pharmcol. 2005;204(3):216-37.

29. Mercado-Lubo R, McCormick BA. The interaction of gut microbes with host ABC transporters. Gut microbes 2010, 1, (5), 301-306.

30. Davidson AL, Chen J. ATP-binding cassette transporters in bacteria. Annual review of biochemistry. 2004;73:241-68.

31. Hou YP, He QQ, Ouyang HM, Peng HS, Wang Q, Li J, Lv XF, Zheng YN, Li SC, Liu HL, Yin AH. Human Gut Microbiota Associated with Obesity in Chinese Children and Adolescents. BioMed research international. 2017;2017:7585989.

32. Gimenez-Bastida JA, Avila-Galvez MA, Espin JC, Gonzalez-Sarrias A. The gut microbiota metabolite urolithin $A$, but not other relevant urolithins, induces p53-dependent cellular senescence in human colon cancer cells. Food chemical toxicology: an international journal published for the British Industrial Biological Research Association. 2020;139:111260.

33. Ma S, You Y, Huang L, Long S, Zhang J, Guo C, Zhang N, Wu X, Xiao Y, Tan H. Alterations in Gut Microbiota of Gestational Diabetes Patients During the First Trimester of Pregnancy. Front Cell Infect Microbiol. 2020;10:58.

34. Dedrick S, Sundaresh B, Huang Q, Brady C, Yoo T, Cronin C, Rudnicki C, Flood M, Momeni B, Ludvigsson J, Altindis E. The Role of Gut Microbiota and Environmental Factors in Type 1 Diabetes Pathogenesis. Front Endocrinol. 2020;11:78.

35. Kazemian N, Mahmoudi M, Halperin F, Wu JC, Pakpour S. Gut microbiota and cardiovascular disease: opportunities and challenges. Microbiome. 2020;8(1):36.

36. Fragiadakis GK, Wastyk HC, Robinson JL, Sonnenburg ED, Sonnenburg JL, Gardner CD, Long-term dietary intervention reveals resilience of the gut microbiota despite changes in diet and weight. The American journal of clinical nutrition 2020.

37. Behera J, Ison J, Tyagi SC, Tyagi N. The role of gut microbiota in bone homeostasis. Bone. 2020;135:115317.

38. Cheng L, Chen Y, Zhang X, Zheng X, Cao J, Wu Z, Qin W, Cheng K. A metagenomic analysis of the modulatory effect of Cyclocarya paliurus flavonoids on the intestinal microbiome in a high-fat dietinduced obesity mouse model. Journal of the science of food and agriculture 2019, 99, (8), 39673975.

39. Nobili S, Lapucci A, Landini I, Coronnello M, Roviello G, Mini E. Role of ATP-binding cassette transporters in cancer initiation and progression. Sem Cancer Biol. 2020;60:72-95.

40. Schuierer MM, Langmann T. Molecular diagnosis of ATP-binding cassette transporter-related diseases. Expert review of molecular diagnostics 2005, 5, (5), 755-67. 
41. Pan WH, Sommer F, Falk-Paulsen $M$, Ulas $T$, Best $P$, Fazio A, Kachroo P, Luzius $A$, Jentzsch $M$, Rehman A, Muller F, Lengauer T, Walter J, Kunzel S, Baines JF, Schreiber S, Franke A, Schultze JL, Backhed F, Rosenstiel P. Exposure to the gut microbiota drives distinct methylome and transcriptome changes in intestinal epithelial cells during postnatal development. Genome medicine. 2018;10(1):27.

42. Frankish A, Diekhans M, Ferreira AM, Johnson R, Jungreis I, Loveland J, Mudge JM, Sisu C, Wright J, Armstrong J, Barnes I, Berry A, Bignell A, Carbonell Sala S, Chrast J, Cunningham F, Di Domenico T, Donaldson S, Fiddes IT, Garcia Giron C, Gonzalez JM, Grego T, Hardy M, Hourlier T, Hunt T, Izuogu OG, Lagarde J, Martin FJ, Martinez L, Mohanan S, Muir P, Navarro FCP, Parker A, Pei B, Pozo F, Ruffier M, Schmitt BM, Stapleton E, Suner MM, Sycheva I, Uszczynska-Ratajczak B, Xu J, Yates A, Zerbino D, Zhang Y, Aken B, Choudhary JS, Gerstein M, Guigo R, Hubbard TJP, Kellis M, Paten B, Reymond A, Tress ML, Flicek, P., GENCODE reference annotation for the human and mouse genomes. Nucleic acids research 2019, 47, (D1), D766-D773.

43. Lin Y, Liu T, Cui T, Wang Z, Zhang Y, Tan P, Huang Y, Yu J, Wang D. RNAlnter in 2020: RNA interactome repository with increased coverage and annotation. Nucleic acids research. 2020;48(D1):D189-97.

44. Kuleshov MV, Jones MR, Rouillard AD, Fernandez NF, Duan Q, Wang Z, Koplev S, Jenkins SL, Jagodnik KM, Lachmann A, McDermott MG, Monteiro CD, Gundersen GW. Ma'ayan, A., Enrichr: a comprehensive gene set enrichment analysis web server 2016 update. Nucleic acids research. 2016;44(W1):W90-7.

\section{Figures}


A

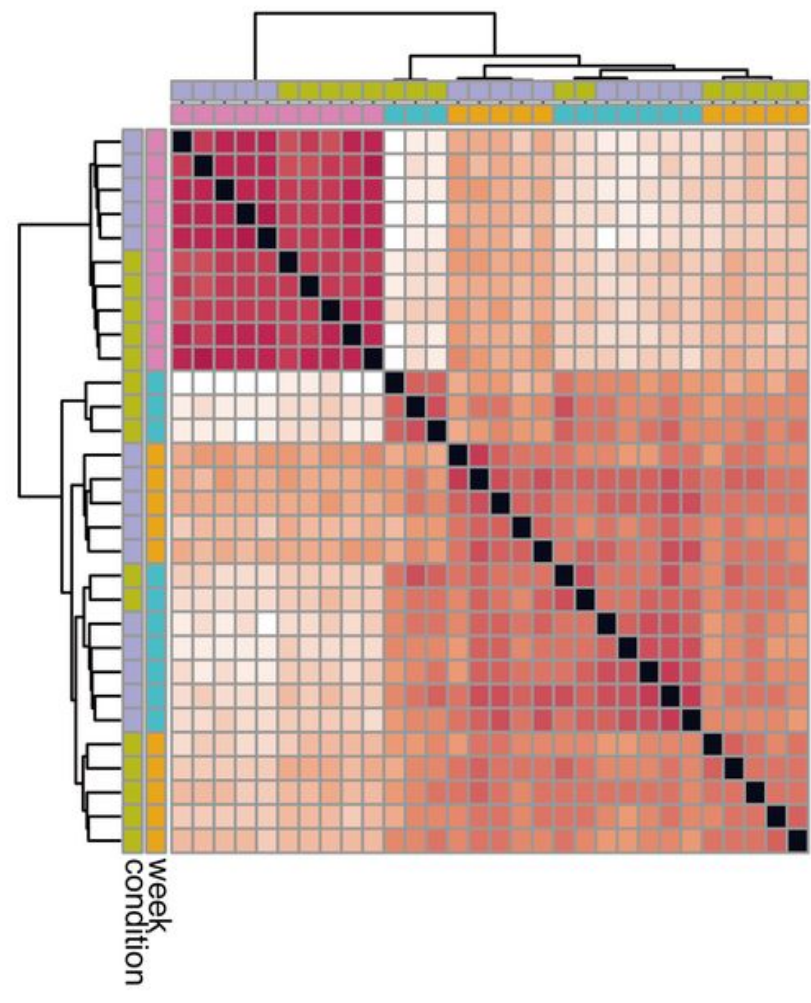

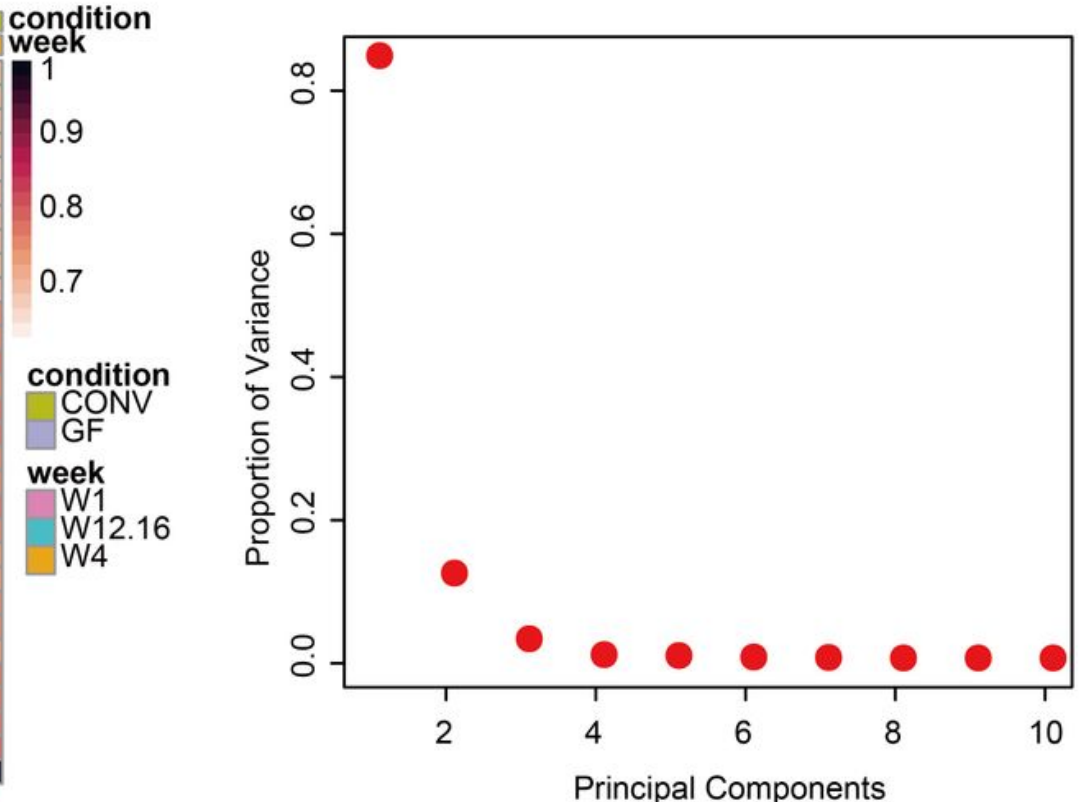

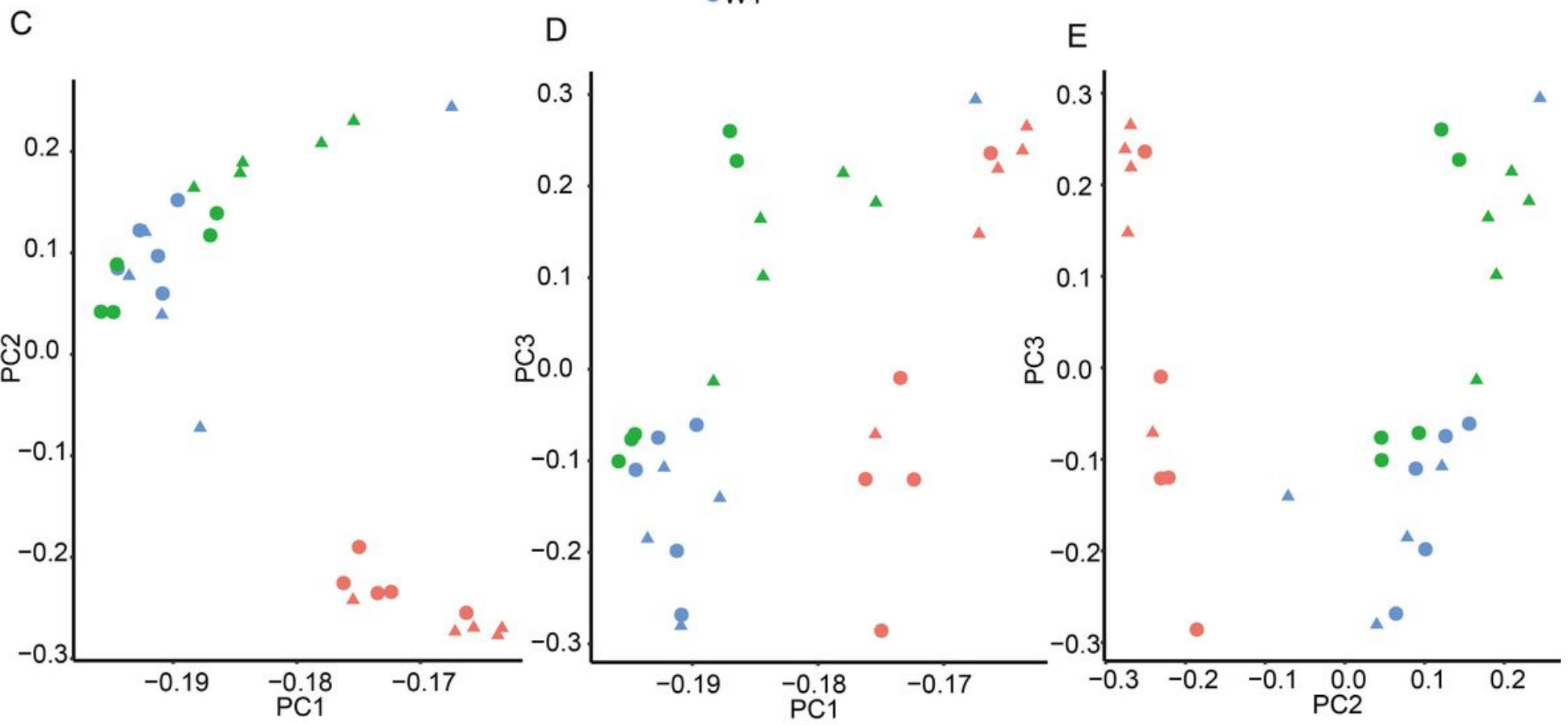

Figure 1

Samples similarity and difference of samples based on IncRNA transcriptome under diverse postnatal development stages and condition. (A) Hierarchical clustering of samples similarity between CONV and GF in the three developmental stages based on IncRNAs. (B) The point plot shows proportion of principal components. (C-E) Multidimensional scaling analysis plot displaying the overall IncRNA profile between CONV and GF in the three developmental stages. 

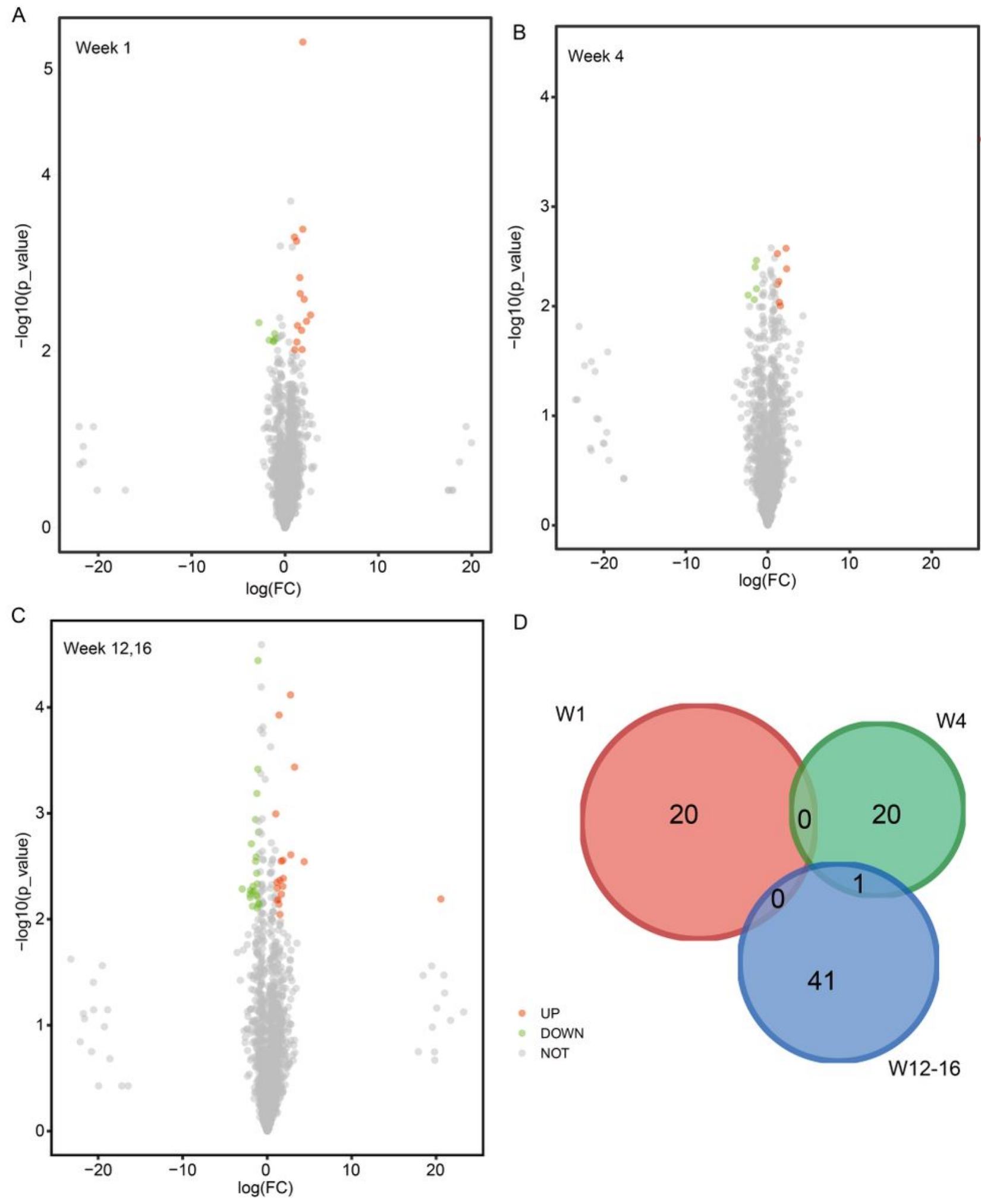

$D$

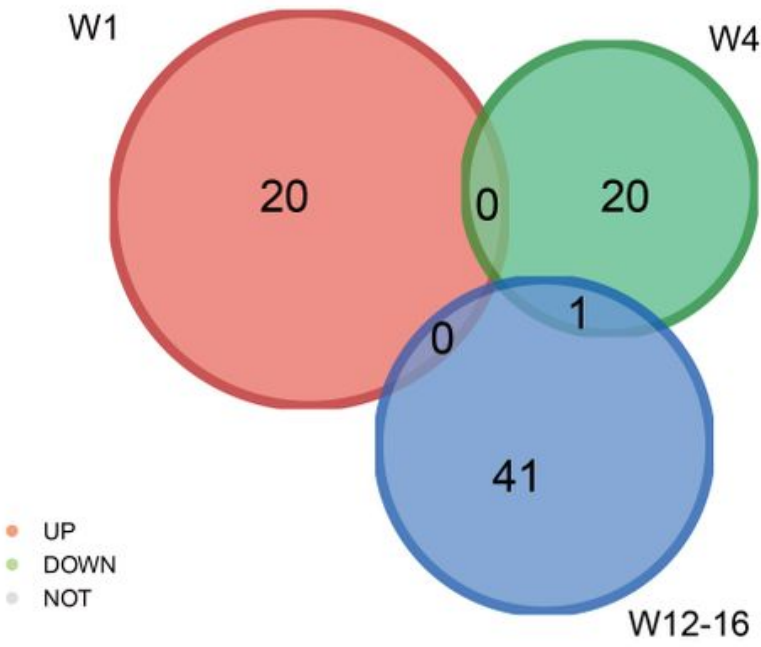

Figure 2

Some IncRNAs were differential expressed between CONV and GF mice in diverse postnatal development stages. (A) Volcano plots show differential expressed IncRNAs in week 1, (B) week 2 and (C) week 12/16. Orange, green and gray represent up-regulated, down-regulated and non-differential expressed IncRNAs. (D) The venn diagram shows intersection of differential expressed IncRNAs among week 1, week 4 and week 12/16. 


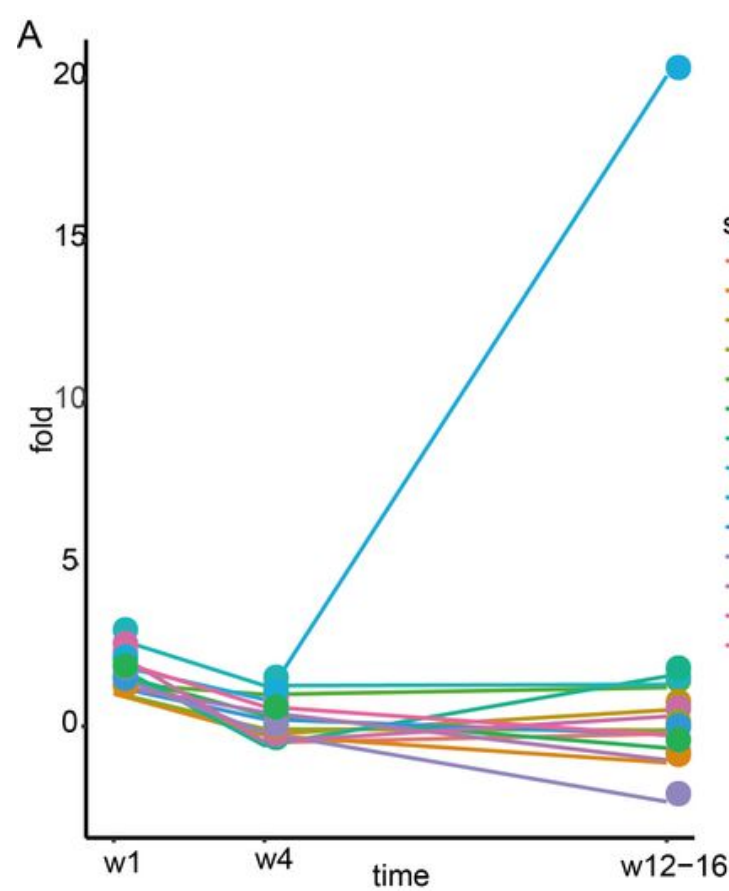

C

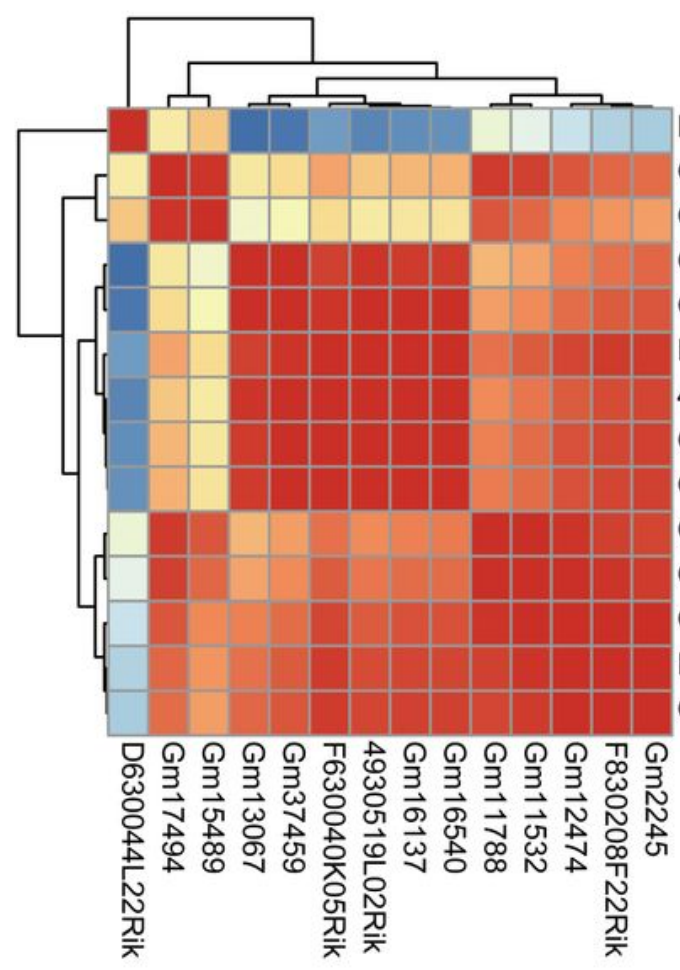

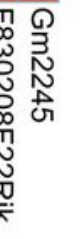

B

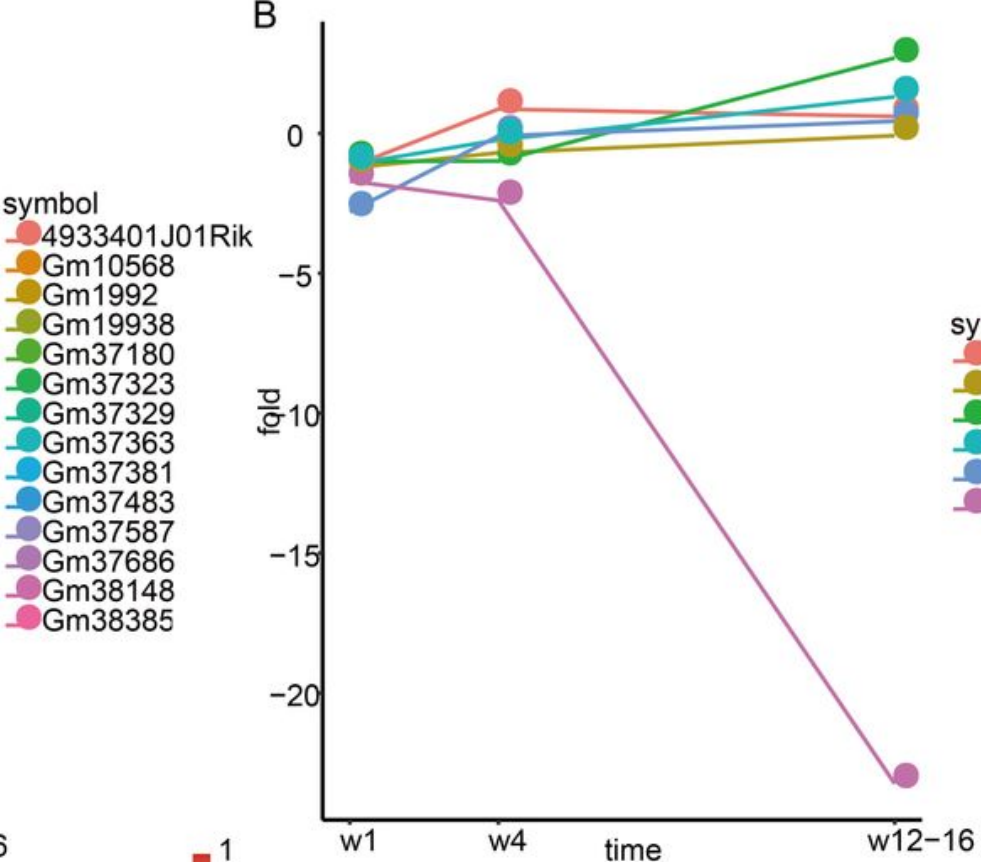

symbol 4933401J01Rik

Gm1992 Gm37180

Gm37329

$\mathrm{Gm} 37363$

Gm37686

0.5

D

$-0.5$

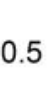

D630044L22Rik

Gm17494

Gm15489

Gm13067

Gm37459

F630040K05Rik 4930519L02Rik

Gm16137

Gm16540

Gm11788

Gm11532

Gm12474

F830208F22Rik

Gm2245

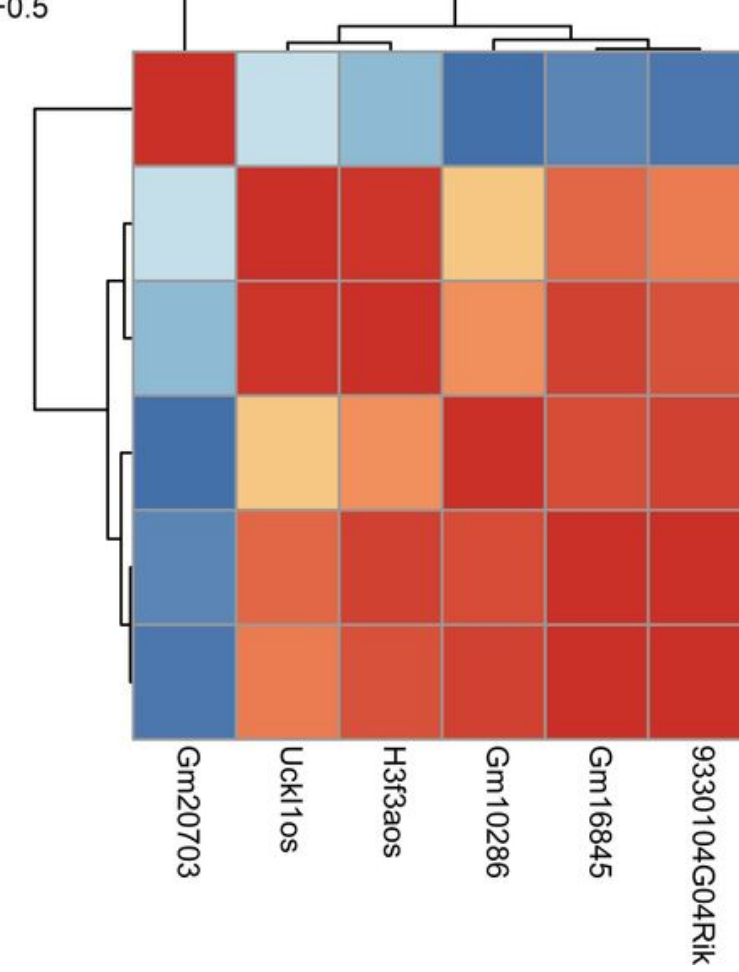

Gm20703

Uckl1os

H3f3aos

Gm10286

Gm16845

9330104G04Rik

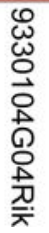

\section{Figure 3}

Differential expressed IncRNAs between CONV and GF mice showed specific features in respective postnatal development stage. (A) The line plots show fold-change values of up-regulated and (B) downregulated IncRNAs in different postnatal development stage. (C) Hierarchical clustering of up-regulated and (D) down-regulated IncRNAs similarity. 


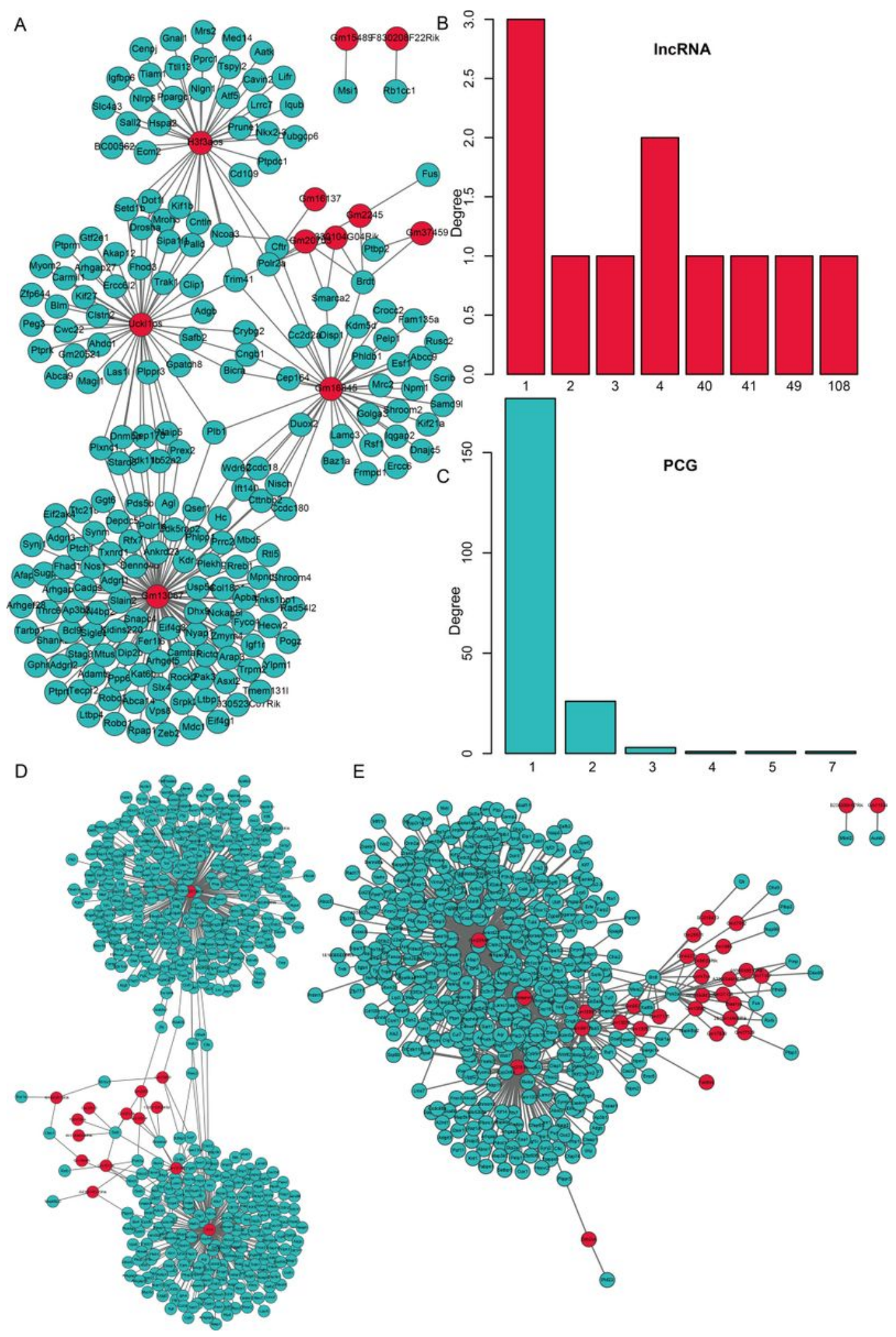

Figure 4

Gut microbiota-specific IncRNA and protein coding gene interaction networks were constructed at different postnatal development stages. (A) The Gut microbiota-specific IncRNA and gene interacted network for week 1. Green and red represent genes and IncRNAs. (B-C) Bar plots show degree of IncRNAs and genes. (D-E) The gut microbiota-specific IncRNA and gene interacted network for week 4 and week $12 / 16$ 

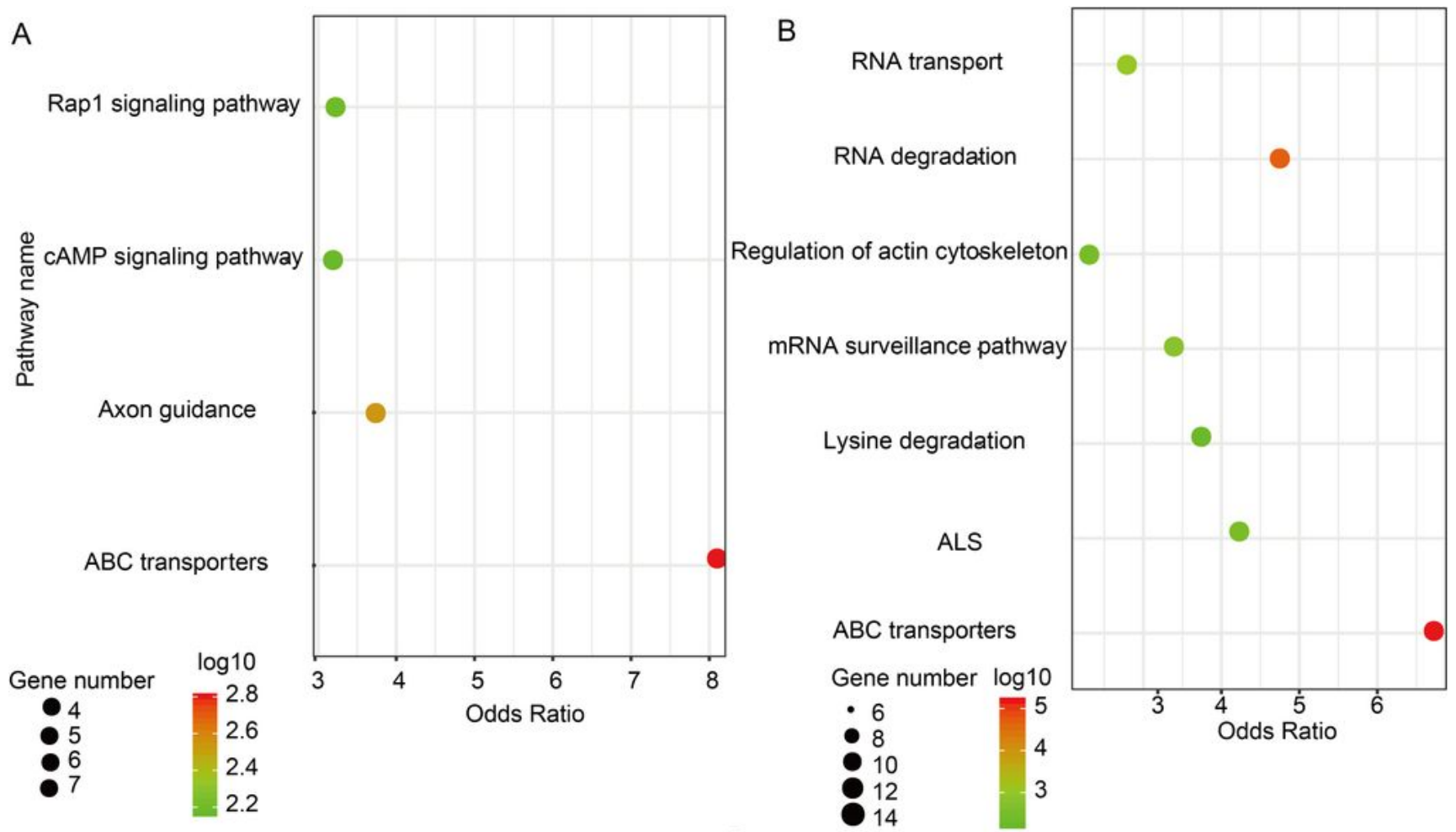

C

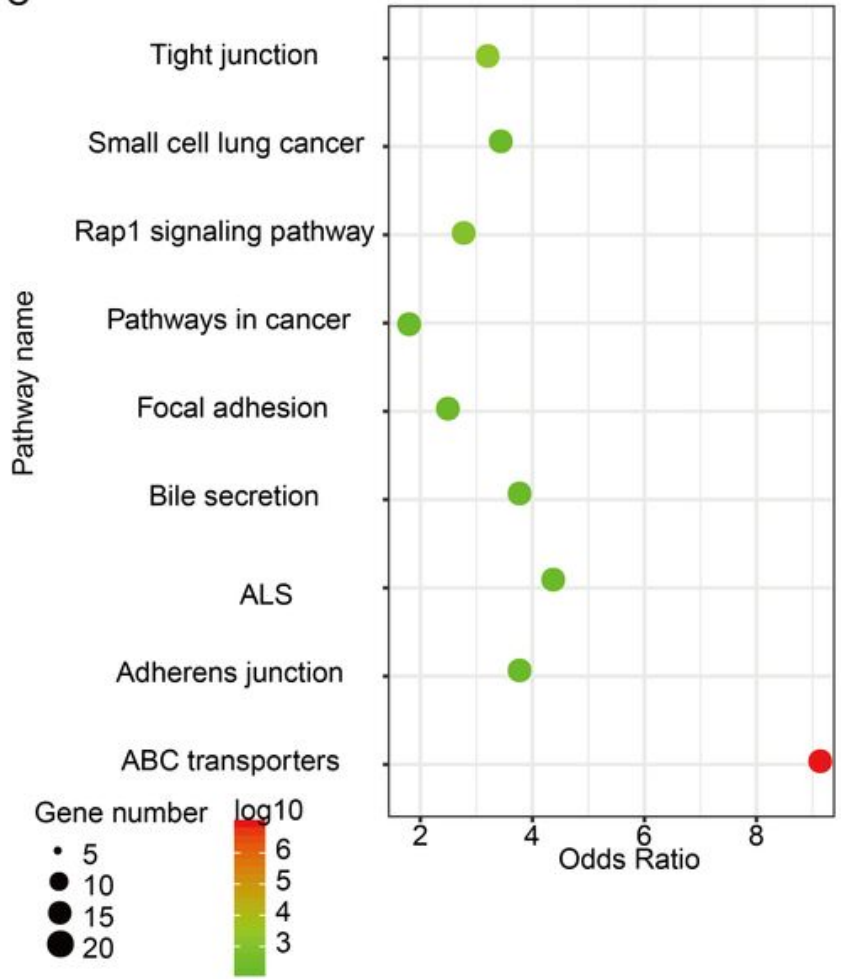

$D$ Eukaryotic-type ABC transporters

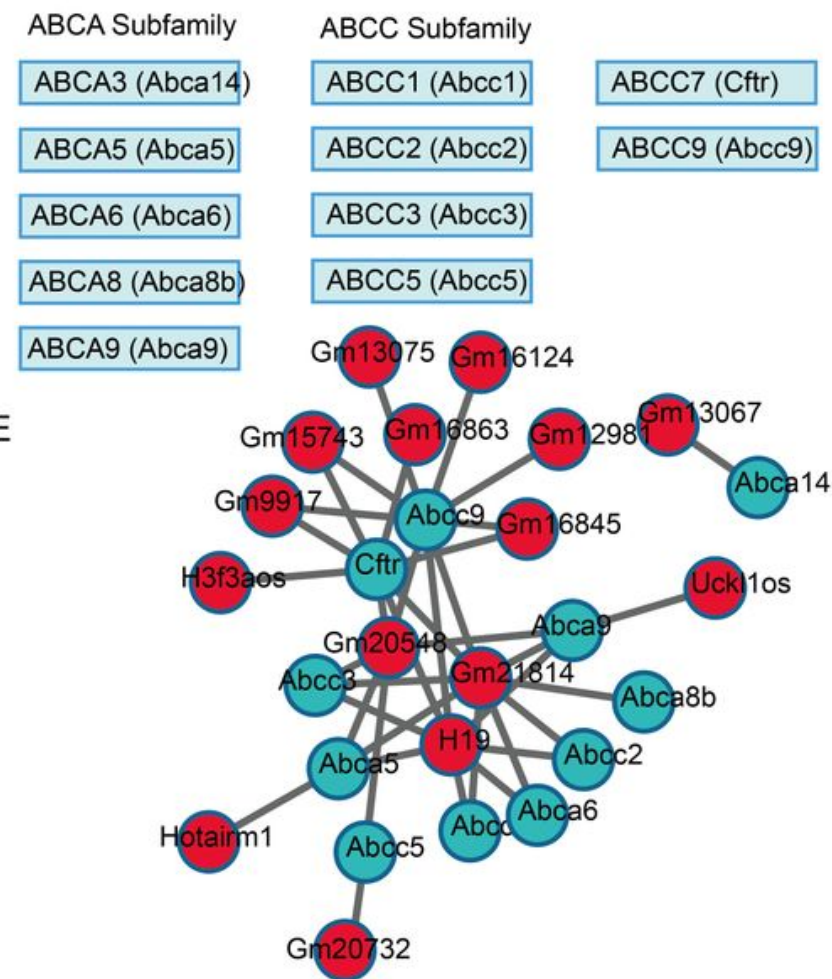

\section{Figure 5}

Functional enrichment analysis of gut microbiota-specific IncRNAs in postnatal development. (A) Points plots show enrichment pathways of gut microbiota-specific IncRNAs in week 1, (B) week 4 and (C) week 12/16. The size of nodes represent numbers of enrichment genes. Red and green represent higher and lower enrichment P-values. (D) ABCA and ABCC subfamilies in eukaryotic-type ABC transporters. (E) gut microbiota-specific IncRNA and ABC transporters-related gene interacted network. 


\section{Supplementary Files}

This is a list of supplementary files associated with this preprint. Click to download.

- FigureS2.tif

- FigureS1.tif

- FigureS3.tif 